\title{
Regulation of Transferrin Receptor Expression and Ferritin Content in Human Mononuclear Phagocytes \\ Coordinate Upregulation by Iron Transferrin and Downregulation by Interferon Gamma
}

Thomas F. Byrd ${ }^{\star}$ and Marcus A. Horwitz

Divisions of Infectious Diseases, Departments of Medicine, School of Medicine, University of California, Los Angeles; and

*West Los Angeles Veterans Affairs Medical Center, Los Angeles, California 90024

\begin{abstract}
We have investigated the regulation of key human iron binding proteins in mononuclear phagocytes by IFN $\gamma$ and iron transferrin. In a previous study, we demonstrated that IFN $\gamma$ downregulates the expression on human monocytes of transferrin receptors, the major source of iron for the cell. In the present study, we show that IFN $\gamma$ also downregulates the intracellular concentration of ferritin, the major iron storage protein in the cell. By radioimmunoassay, the mean ferritin content of nonactivated monocytes was $\mathbf{3 6 1} \pm \mathbf{1 0 7} \mathrm{fg} /$ monocyte (mean \pm SEM) whereas the mean ferritin content of IFN $\gamma$-activated monocytes was $64 \pm 13 \mathrm{fg} /$ monocyte, an $82 \%$ reduction with activation ( $P$ $<0.01, t$ test). Consistent with its downregulating effect on these iron proteins, IFN $\gamma$ treatment also results in decreased iron incorporation. IFN $\boldsymbol{\gamma}$-activated monocytes incorporated 33\% less iron from ${ }^{59} \mathrm{Fe}$-transferrin than nonactivated monocytes $(P<0.05, t$ test $)$. Gel filtration chromatography revealed that incorporated iron is located primarily in ferritin in both nonactivated and IFN $\boldsymbol{\gamma}$-activated monocytes. Ferritin in IFN $\boldsymbol{\gamma}$ activated monocytes is saturated with approximately three times as much ${ }^{59} \mathrm{Fe}$ as ferritin in nonactivated monocytes.

We have also explored the effect of iron transferrin on transferrin receptor expression and intracellular ferritin content in human monocytes. We have found that iron transferrin markedly upregulates both transferrin receptor expression and intracellular ferritin content in both nonactivated (2.3- and 1.3fold, respectively) and IFN $\gamma$-activated (3.4- and 2.9-fold, respectively) monocytes.

This study demonstrates that transferrin receptor expression and intracellular ferritin content in human monocytes is unidirectionally and coordinately upregulated by iron transferrin and unidirectionally and coordinately downregulated by IFN $\gamma$. (J. Clin. Invest. 1993. 91:969-976.) Key words: iron • macrophage $\bullet$ cytokines $\bullet$ Legionella pneumophila $\bullet$ tumor necrosis factor alpha
\end{abstract}

\section{Introduction}

Iron homeostasis and macrophage physiology are tightly intertwined. Macrophages play a central role in maintaining iron

This paper was presented in part at the National Meeting of the Association of American Physicians, the American Society for Clinical Investigation, and the American Federation for Clinical Research, 4-7 May 1990, Washington, DC.

Address correspondence to Dr. Thomas F. Byrd, West Los Angeles Veterans Affairs Medical Center, Wilshire and Sawtelle, W-111F, Building 500, Room 3221, Los Angeles, CA 90073.

Received for publication 10 January 1992 and in revised form 29 September 1992.

The Journal of Clinical Investigation, Inc.

Volume 91, March 1993, 969-976 homeostasis, serving as one of the major iron storage organs of the human body (1). Iron in turn plays a major role in macrophage interactions with intracellular and extracellular pathogens, possibly serving as a catalyst in the generation of toxic oxygen metabolites used in antimicrobial defense and serving as an essential nutrient for intracellular parasites $(2,3)$. In particular, our work with Legionella pneumophila has demonstrated the importance of mononuclear phagocyte iron metabolism to intracellular parasitism. In previous studies, we have reported that monocytes activated with IFN $\gamma$, cultured with apolactoferrin, or incubated with the weak bases chloroquine and ammonium chloride inhibit Legionella pneumophila intracellular multiplication by limiting the availability of intracellular iron (3-5).

The interplay between macrophages and iron is under the influence of environmental factors that regulate macrophage molecules involved in iron uptake and storage, including transferrin receptors, which mediate endocytosis of iron-transferrin, the major source of iron for the cell, and ferritin, the major iron storage protein of the cell. In this paper, we have sought to gain a better understanding of regulation of iron molecules by exploring the influence of two important environmental stimuli, IFN $\gamma$ and iron transferrin, on transferrin receptor expression and intracellular ferritin concentration in human mononuclear phagocytes. In a previous study, we reported that IFN $\gamma$ activated monocytes downregulate transferrin receptor expression (3). In this study, we shall demonstrate that IFN $\gamma$ activated monocytes also downregulate the concentration of intracellular ferritin. In this study, we shall also demonstrate that iron-transferrin upregulates both transferrin receptor expression and intracellular ferritin concentration in both IFN $\gamma$ activated and nonactivated monocytes.

\section{Methods}

Media. RPMI 1640 medium with L-glutamine (RPMI) and Iscove's modified Dulbecco's medium were obtained from Gibco Laboratories, Grand Island, NY. PBS containing 1\% BSA (PBS-BSA) was prepared as described (6).

Reagents. Iron transferrin (Sigma Chemical Co., St. Louis, MO) was dissolved in RPMI or Iscove's medium and then filtered through $0.22-\mu \mathrm{m}$ filter units. $\mathrm{Fe}^{59}$ transferrin was prepared using apotransferrin (Miles Scientific, Kankakee, IL) and $\mathrm{Fe}^{59}$ chloride (ICN Nutritional Biochemicals, Cleveland, $\mathrm{OH}$ ) as described (7). Human recombinant IFN $\gamma$ was a gift from Genentech Inc., South San Francisco, CA, and was reconstituted and stored as previously described (3).

Human blood mononuclear cells. Mononuclear cells were obtained from the blood of healthy, adult volunteers by centrifugation over a Ficoll-sodium diatrizoate solution (Pharmacia Fine Chemicals, Piscataway, $\mathrm{NJ}$ ) as previously described (6). In experiments in which intracellular ferritin content was measured, monocyte- and lymphocyteenriched cell populations were obtained by centrifugation of the blood mononuclear cell fraction on preformed Percoll gradients as des cribed (3). 
Assay for intracellular ferritin content of nonactivated and IFN $\gamma$ activated monocytes. Monocyte-enriched and lymphocyte-enriched cell suspensions were isolated as described above. Monocytes were cultured in screw cap Teflon wells (Savillex Corp., Minnetonka, MN) at a concentration of $1.5-2.0 \times 10^{6}$ cells $/ \mathrm{ml}$ in RPMI containing $20 \%$ autologous serum, in Iscove's containing $1 \%$ autologous serum and 200 $\mu \mathrm{g} / \mathrm{ml}$ iron-saturated transferrin, or in Iscove's alone. Lymphocytes were cultured in screw cap Teflon wells at a concentration of 2.0 $\times 10^{6} / \mathrm{ml}$ in RPMI containing $20 \%$ autologous serum. Cells were incubated with IFN $\gamma(2 \mu \mathrm{g} / \mathrm{ml}$, equivalent to $20,000 \mathrm{U} / \mathrm{ml})$ or control buffer (PBS-BSA) at $37^{\circ} \mathrm{C}$ in $5 \% \mathrm{CO}_{2}: 95 \%$ air for $5 \mathrm{~d}$. A portion of the cells were then either processed for flow cytometric analysis, as described below, or cyto-centrifuged onto a glass slide (Shandon Southern Instruments Inc., Sewickley, PA) and stained with alpha naphthyl acetate esterase (Sigma Chemical Co.) to determine the percentage of monocytes in the cell preparation. The remaining cells were washed with RPMI medium twice, resuspended in PBS-BSA or $0.1 \%$ Triton $X-100$, and disrupted with a probe tip sonicator (Ultrasonics, Farmingdale, NY) for 2 min using a microtip probe, $30 \%$ discontinuous pulsation, and a power output setting of 4 . The cell lysates were centrifuged at $15,000 \mathrm{~g}$ for $10 \mathrm{~min}$ in a refrigerated microcentrifuge (Savant Instruments Inc., Hicksville, NY) to remove any insoluble material and the ferritin content of the supernates was measured using a radioimmunoassay with either rabbit polyclonal antisera against human liver ferritin or mouse monoclonal antibody against human liver ferritin (Micromedic Systems; ICN, Horsham, PA). When tested against the same subject's samples, both radioimmunoassays gave identical results.

Assay for iron incorporation by nonactivated and IFN $\mathrm{F}$-activated human monocytes. Monocyte-enriched cell suspensions were prepared as described above and cultured in Teflon wells in Iscove's containing $1 \%$ autologous serum and $\mathrm{Fe}^{59}$ transferrin at a concentration of 200 or $15 \mu \mathrm{g} / \mathrm{ml}$ (sp act $1,400-10,000 \mathrm{cpm} / \mu \mathrm{g}$ transferrin), with or without IFN $\gamma(2 \mu \mathrm{g} / \mathrm{ml})$. After $5 \mathrm{~d}$, the cells were harvested as described (3) and washed twice in PBS-BSA at $200 \mathrm{~g}$ for $10 \mathrm{~min}$ using a refrigerated microcentrifuge (Savant Instruments Inc.). A sample of the cell suspension was removed and stained with esterase to determine the percentage of contaminating lymphocytes (esterase-negative) in the preparation as in the assay described above. The remaining cells were assayed for incorporated $\mathrm{Fe}^{59}$ by counting cell-associated radioactivity with a gamma counter (Biogamma II; Beckman Instruments, Inc., Fullerton, CA). In some experiments, these cells were then aliquoted to $12 \times 75$ mm polystyrene tubes (2054; Falcon Labware, Becton, Dickinson, \& Co., Oxnard, CA) in Iscove's medium with deferoxamine mesylate (Ciba-Geigy, Summit, NJ) at a concentration of $25 \mu \mathrm{M}$ with or without IFN $\gamma$ and incubated at $37^{\circ} \mathrm{C}$ in $5 \% \mathrm{CO}_{2}-95 \%$ air. At 3,9 , and $18 \mathrm{~h}$, the cells were centrifuged at $150 \mathrm{~g}$ for $10 \mathrm{~min}$ and the supernate removed. The cells were assayed for $\mathrm{Fe}^{59}$ by counting cell-associated radioactivity with a gamma counter.

Localization of incorporated iron in nonactivated and IFN $\mathrm{\gamma}$-activated human monocytes. Monocyte-enriched cell suspensions were cultured in Teflon wells in Iscove's containing $1 \%$ autologous serum and $200 \mu \mathrm{g} / \mathrm{ml} \mathrm{Fe}^{59}$ transferrin, with or without IFN $\gamma(2 \mu \mathrm{g} / \mathrm{ml})$. After $5 \mathrm{~d}$, the monocytes were harvested, resuspended in PBS containing 70 $\mu \mathrm{m}$ deferoxamine (Ciba-Geigy) to bind immediately any free iron released from the cells, and $0.1 \%$ Triton X-100. The cells were lysed with a probe tip sonicator as described above. The lysate was centrifuged at $15,000 \mathrm{~g}$ for $10 \mathrm{~min}$ in a refrigerated microcentrifuge (Savant Instruments Inc.) and radioactivity in the supernate and pellet was measured with a gamma counter. The supernate was then applied to an ultrogel ACA-34 (IBF, 20,000-350,000; Biotechnics) column precalibrated with transferrin, ferritin, lactalbumin, and dinitrophenol. In some experiments, a portion of the cells from the same experiment were incubated with unlabeled iron transferrin at a concentration of $200 \mu \mathrm{g} / \mathrm{ml}$ and assayed for intracellular ferritin as described above.

Assay for transferrin receptor expression on nonactivated and IFN $\gamma$-activated monocytes using flow cytometry. Monocyte-enriched cell suspensions were prepared as described above. The monocytes were cultured in Teflon wells in RPMI containing $20 \%$ autologous serum, with or without IFN $\gamma(2 \mu \mathrm{g} / \mathrm{ml})$, and with or without iron transferrin $(6 \mathrm{mg} / \mathrm{ml})$. After $5 \mathrm{~d}$, a portion of the cells in each experiment was assayed for intracellular ferritin content as described above. The remaining cells were prepared for flow cytometric analysis as previously described (3). Flow cytometric analysis of the cells was performed on a FACScan ${ }^{\circledR}$ flow cytometer (Becton Dickinson Immunocytometry Systems, San Jose, CA), equipped with a 15 MW $488 \mathrm{~nm}$ air-cooled argon-ion laser. The flow cytometer was gated on forward scatter and side scatter so as to include monocytes and contaminating lymphocytes, and exclude cell debris, clumps, and nonviable cells. Green FITC fluorescence of 15,000 cells in this gate was detected with a $530 \pm 30 \mathrm{~nm}$ band pass filter in front of the photomultiplier tube. That nonviable cells were excluded from this gate was confirmed in early experiments by analyzing cell suspensions treated with propidium iodide. Single parameter analysis using single histograms and corresponding statistics was used.

Analysis of cells incubated without antibody using a single parameter histogram showed that the monocytes and contaminating lymphocytes separated into two distinct peaks of fluorescence intensity reflecting autofluorescence, with the monocyte peak having the higher fluorescence intensity. The location of these peaks was the same for cells incubated with isotypic control $\mathrm{mAb}$. However, when cells were incubated with anti-transferrin receptor $\mathrm{mAb}$, the monocyte peak was shifted to a higher level of fluorescence intensity consistent with the presence of transferrin receptors on this cell population, but the lymphocyte peak was not shifted, consistent with a lack of transferrin receptors on these nonproliferating lymphocytes. The mean relative linear fluorescence of the monocyte peak was obtained by determining the difference between the mean relative linear fluorescence of monocytes incubated with antitransferrin receptor $\mathrm{mAb}$ and the mean relative linear fluorescence of monocytes incubated with isotypic control $\mathrm{mAb}$. In experiments in which a portion of the cells was assayed for intracellular ferritin, the percentage of contaminating lymphocytes was determined from the lymphocyte peak on the single parameter histogram in each sample.

\section{Results}

IFN $\gamma$-activated monocytes downregulate intracellular ferritin content. To examine the effect of IFN $\gamma$ activation on monocyte intracellular ferritin content, we treated monocytes with IFN $\gamma$ or control medium for $5 \mathrm{~d}$ and measured ferritin levels with a radioimmunoassay. In this set of experiments, we cultured nonactivated and IFN $\gamma$-activated monocytes in Iscove's medium containing $1 \%$ autologous serum and $200 \mu \mathrm{g} / \mathrm{ml}$ iron transferrin. These low serum conditions were chosen so that in parallel experiments designed to measure $\mathrm{Fe}^{59}$ uptake, competition for the transferrin receptor between transferrin in serum and $\mathrm{Fe}^{59}$ transferrin would be minimized. We assayed ferritin twice in 5-d monocytes from each of four subjects in eight independent experiments (Table I). In the monocytes of any one subject, there was little variability in ferritin content from one experiment to the next. However, there was considerable variability in ferritin content among monocytes from different individuals. A similar pattern of variability was observed for transferrin receptor expression in a previous study (3). The mean ferritin content of nonactivated monocytes was $361 \pm 107$ $\mathrm{fg} /$ monocyte $($ mean \pm SEM) with a range of 178-638 ( $P$ $<0.01$, paired, two-tailed $t$ test). Whatever the ferritin content in the nonactivated monocytes of a subject, the amount of ferritin in the IFN $\gamma$-activated monocytes of the same subject was markedly decreased for all subjects. The mean ferritin content of activated monocytes was $89 \pm 25 \mathrm{fg} /$ monocyte 
Table I. Ferritin Levels Are Decreased in IFN $\gamma$-activated Human Monocytes

\begin{tabular}{|c|c|c|c|}
\hline \multirow[b]{2}{*}{ Subject } & \multicolumn{2}{|c|}{ Intracellular ferritin } & \multirow{2}{*}{$\begin{array}{l}\text { Percent } \\
\text { reduction } \\
\text { with } \\
\text { activation }\end{array}$} \\
\hline & Nonactivated & Activated & \\
\hline \multicolumn{4}{|c|}{$f g /$ monocyte (mean $\pm S D$ ) } \\
\hline 1 & $178 \pm 3$ & $38 \pm 16$ & 79 \\
\hline 2 & $421 \pm 13$ & $84 \pm 1$ & 80 \\
\hline 3 & $206 \pm 10$ & $43 \pm 4$ & 79 \\
\hline 4 & $638 \pm 37$ & $89 \pm 25$ & 86 \\
\hline Mean \pm SEM & $361 \pm 107$ & $64 \pm 13$ & 82 \\
\hline
\end{tabular}

Intracellular ferritin content of nonactivated and IFN $\gamma$-activated monocytes was measured by radioimmunoassay twice on each of four subjects in eight independent experiments. Data are the mean $\pm \mathrm{SD}$ of the two measurements of intracellular ferritin content for each subject, and the mean \pm SEM of ferritin content of all subjects. $P$ $<0.01$ by paired, two-tailed $t$ test.

( mean \pm SEM), an $82 \%$ reduction from the mean level in nonactivated monocytes.

In the experiments described above, monocytes were cultured in the presence of small amounts of autologous serum. Serum may impact on macrophage physiology such as the expression of certain markers of maturation $(8,9)$. To determine if iron regulation is altered under serumless conditions, we assessed intracellular ferritin content and transferrin receptor expression on IFN $\gamma$-activated monocytes cultured in the absence of serum. In two independent experiments on monocytes from the same individual, ferritin levels in nonactivated monocytes cultured in the absence of serum were reduced compared with the levels in monocytes cultured in the presence of serum. Ferritin levels in monocytes cultured in the absence of serum were reduced further ( $39 \%$ ) by IFN $\gamma$ activation. In these same experiments, transferrin receptor expression on nonactivated and IFN $\gamma$-activated monocytes cultured under serumless conditions was comparable to that of nonactivated and IFN $\gamma$ activated monocytes cultured in the presence of serum. Thus, under serumless conditions, mean transferrin receptor expression on IFN $\gamma$-activated monocytes was reduced $84 \%$ from the level on nonactivated monocytes, a reduction comparable to that of monocytes cultured in the presence of serum.

The concentration of ferritin in freshly isolated, unstimulated blood monocytes is 7.5 times that in freshly isolated blood lymphocytes (10). As monocytes mature into macrophages in culture, ferritin content markedly increases, consistent with the role of tissue macrophages as an iron storage organ (11). In contrast, the ferritin content of lymphocytes remains unchanged with time in culture (10). The small amount of ferritin present in lymphocytes stores the minimal requirement of iron necessary for cell functions. With mitogenic stimulation, the intracellular ferritin concentration is downregulated as the cell mobilizes for cellular proliferation (12).

In view of these considerations, we anticipated that ferritin concentrations in lymphocytes contaminating the monocyte preparation would be very low and thus inconsequential. Nevertheless, to assess the potential influence of ferritin from contaminating lymphocytes on the results of this assay, we radioim- munoassayed ferritin in an enriched population of 5-d-old lymphocytes and 5-d-old monocytes from the same individual at the same time. The lymphocytes had $15 \mathrm{fg}$ of ferritin per cell compared with $348 \mathrm{fg}$ per monocyte. The ferritin detected in the lymphocytes could be accounted for by contaminating monocytes in the lymphocyte-enriched preparation.

IFN $\gamma$-activated monocytes incorporate less iron from iron transferrin than nonactivated monocytes. Since IFN $\gamma$-activated monocytes downregulate both transferrin receptor expression and intracellular ferritin content, we hypothesized that they incorporate less iron than nonactivated monocytes. To explore this, we incubated IFN $\gamma$-activated and nonactivated monocytes with $\mathrm{Fe}^{59}$ transferrin for $5 \mathrm{~d}$, and measured the total amount of monocyte-associated radioactive iron. We performed two determinations on each of three subjects in six independent experiments. In four of the six experiments, we incubated monocytes with $200 \mu \mathrm{g} / \mathrm{ml} \mathrm{Fe}^{59}$ transferrin. This concentration was chosen because it represents the amount of iron-saturated transferrin present in $20 \%$ serum, the serum concentration used in our previous studies. In two of the experiments, we used a less concentrated preparation of $\mathrm{Fe}^{59}$ transferrin. In these experiments, we incubated monocytes with 15 $\mu \mathrm{g} / \mathrm{ml} \mathrm{Fe}^{59}$ transferrin, a concentration limited by volume considerations, but added a similar number of cpm to the monocytes. In all three subjects tested, IFN $\gamma$-activated monocytes consistently incorporated less iron than nonactivated monocytes. Overall, there was a $33 \%$ reduction in iron uptake with IFN $\gamma$-activation $(P<0.05$ paired, two-tailed $t$ test $)$. In the four experiments in which monocytes were cultured with $200 \mu \mathrm{g} /$ $\mathrm{ml} \mathrm{Fe} \mathrm{F}^{59}$ transferrin, nonactivated monocytes incorporated $2.96 \pm 0.63 \mathrm{fg} /$ monocyte (mean $\pm \mathrm{SEM}$ ) whereas IFN $\gamma$-activated monocytes incorporated $1.80 \pm 0.24 \mathrm{fg} /$ monocyte ( mean \pm SEM) (Fig. 1), a 39\% reduction with activation. In the two experiments in which monocytes were cultured with 15 $\mu \mathrm{g} / \mathrm{ml} \mathrm{Fe} \mathrm{e}^{59}$ transferrin, nonactivated monocytes incorporated $0.24 \pm 0.02 \mathrm{fg} /$ monocyte (mean $\pm \mathrm{SEM}$ ) whereas IFN $\gamma$-activated monocytes incorporated $0.17 \pm 0.02 \mathrm{fg} /$ monocyte, a $30 \%$ reduction with activation. As we have seen with both transferrin receptor expression and ferritin content, there was much

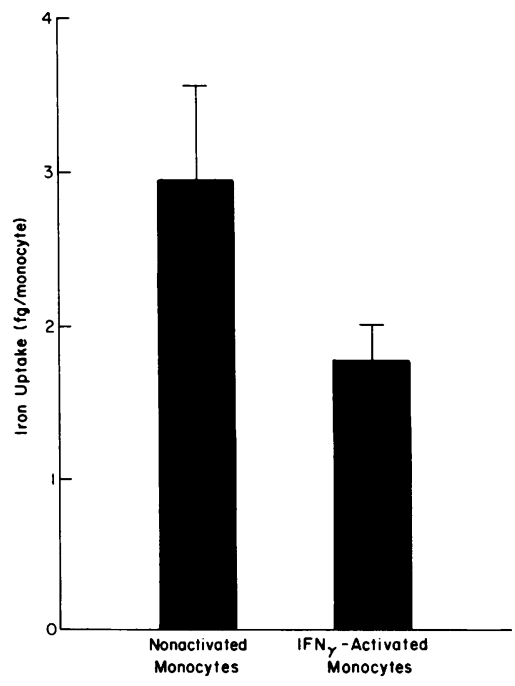

Figure 1. IFN $\gamma$-activated monocytes incorporate less iron from iron transferrin than nonactivated monocytes. Iron incorporation was measured in nonactivated and IFN $\gamma$ activated monocytes from each of three subjects in four independent experiments in parallel with measurements of intracellular ferritin levels. Nonactivated and IFN $\gamma$-activated monocytes were incubated with $\mathrm{Fe}^{59}$ transferrin $(200 \mu \mathrm{g} / \mathrm{ml})$ for $5 \mathrm{~d}$, and monocyte-

associated radioactivity was determined. Data are the mean \pm SEM for all subjects. 
less variability in the iron content of IFN $\gamma$-activated monocytes compared with that of nonactivated monocytes.

It has been proposed that ferritin turnover within the cell occurs by degradation in lysosomes with release of iron. This raised the possibility that the difference in iron incorporation between nonactivated and IFN $\gamma$-activated monocytes may be due to increased turnover and release of iron by the IFN $\gamma$ activated monocytes. To examine this possibility, we incubated nonactivated and IFN $\gamma$-activated monocytes with $\mathrm{Fe}^{59}$ transferrin for $5 \mathrm{~d}$ and measured cell-associated radioactivity. We then reincubated the monocytes with or without IFN $\gamma$ in Iscove's medium under serumless conditions in the presence of $25 \mu \mathrm{M}$ deferoxamine, which served as an iron acceptor. At 3, 9, and $18 \mathrm{~h}$ we observed a parallel, progressive loss of iron in the two groups of monocyte cultures such that by $18 \mathrm{~h}$, the nonactivated monocytes had lost $46 \%$ of their iron and the IFN $\gamma$ activated monocytes had lost $49 \%$ of their iron. Thus, increased iron release by the IFN $\gamma$-activated monocytes does not account for the decreased iron incorporation in these cells.

Iron from iron transferrin is incorporated into intracellular ferritin in both nonactivated and IFN $\gamma$-activated monocytes. We next investigated the distribution of incorporated iron in nonactivated and IFN $\gamma$-activated monocytes. To do this, we incubated monocytes with $\mathrm{Fe}^{59}$ transferrin for $5 \mathrm{~d}$, harvested

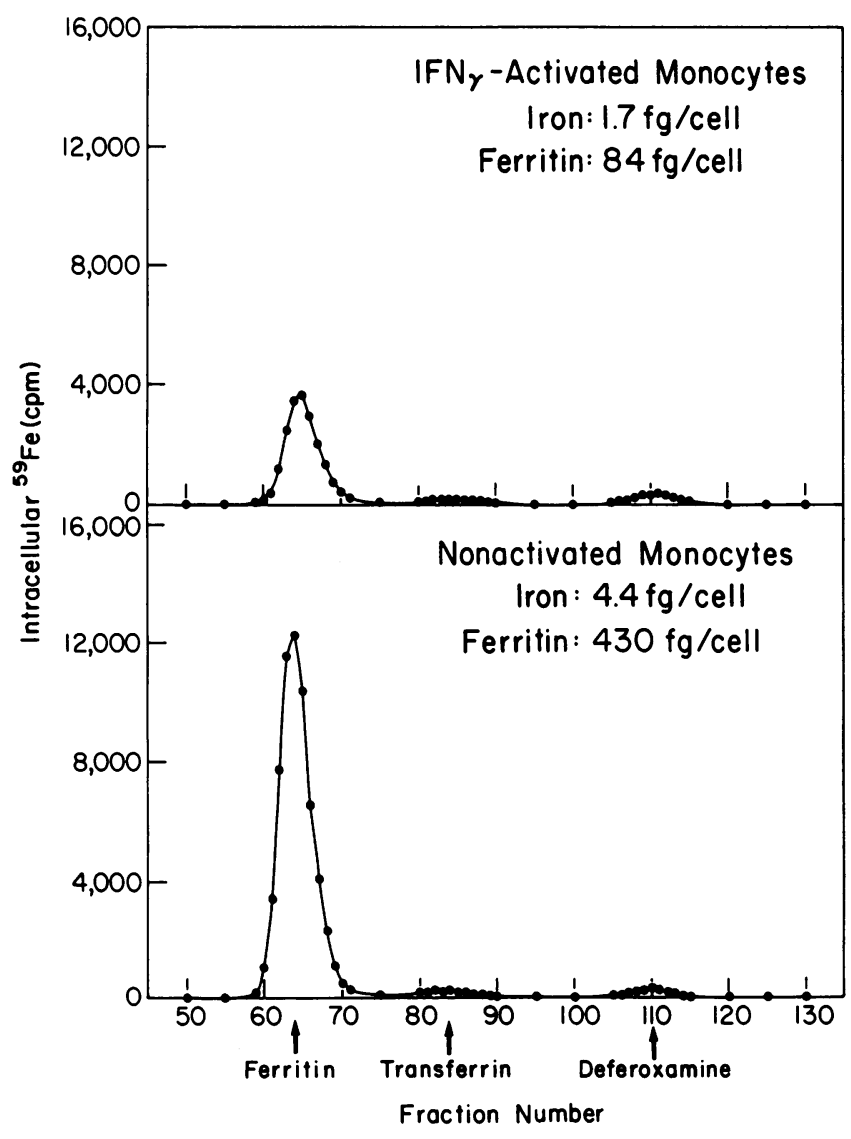

Figure 2. Iron from iron transferrin is incorporated primarily into intracellular ferritin in both nonactivated and IFN $\gamma$ activated monocytes. Nonactivated and IFN $\gamma$-activated monocytes were incubated with $\mathrm{Fe}^{59}$ transferrin. After $5 \mathrm{~d}$, the monocytes were lysed in the presence of deferoxamine, and the lysates run on a precalibrated ACA-34 gel filtration column. Radioactivity of each of the fractions was measured using a gamma counter. The locations where ferritin, transferrin, and deferoxamine come off the column are indicated. them, lysed them in the presence of deferoxamine, and analyzed the lysates on a precalibrated gel filtration column. We added the iron chelator deferoxamine, which does not remove significant amounts of iron from ferritin or transferrin under in vitro conditions $(13,14)$, to allow us to determine what portion of incorporated iron within the cell was not bound to these iron binding proteins. We performed four independent experiments on three subjects. The great majority of measurable radioactivity that came off the column was concentrated in a single large peak corresponding to the location of ferritin on the column (Fig. 2). A small peak of radioactivity, $<10 \%$ of the total counts off the column, came off the column at the location of transferrin, and probably represented transferrin within the monocytes before lysis. Finally, another small peak of radioactivity, again $<10 \%$ of the total counts, came off the column at the location for deferoxamine, indicating that the majority of iron within the cells was bound to intracellular ferritin.

Since nearly all of the radioactive iron incorporated into nonactivated and IFN $\gamma$-activated monocytes was incorporated into intracellular ferritin, we could determine the extent to which ferritin was saturated with newly incorporated iron by measuring iron incorporation and intracellular ferritin content . in monocytes from the same individual at the same time. The results of four independent experiments on three subjects revealed that ferritin in IFN $\gamma$-activated monocytes is saturated with approximately three times as much $\mathrm{Fe}^{59}$ as ferritin in nonactivated monocytes (Fig. 3).

Iron transferrin upregulates transferrin receptor expression and ferritin levels both in IFN $\gamma$-activated and nonactivated monocytes. Iron salts have been previously shown to upregulate transferrin receptor expression and intracellular ferritin in nonactivated human monocytes (5). We next sought to determine the effect of the physiologic iron binding protein transferrin on transferrin receptor expression in nonactivated and interferon gamma-activated human monocytes. To explore this, we cultured nonactivated and IFN $\gamma$-activated monocytes

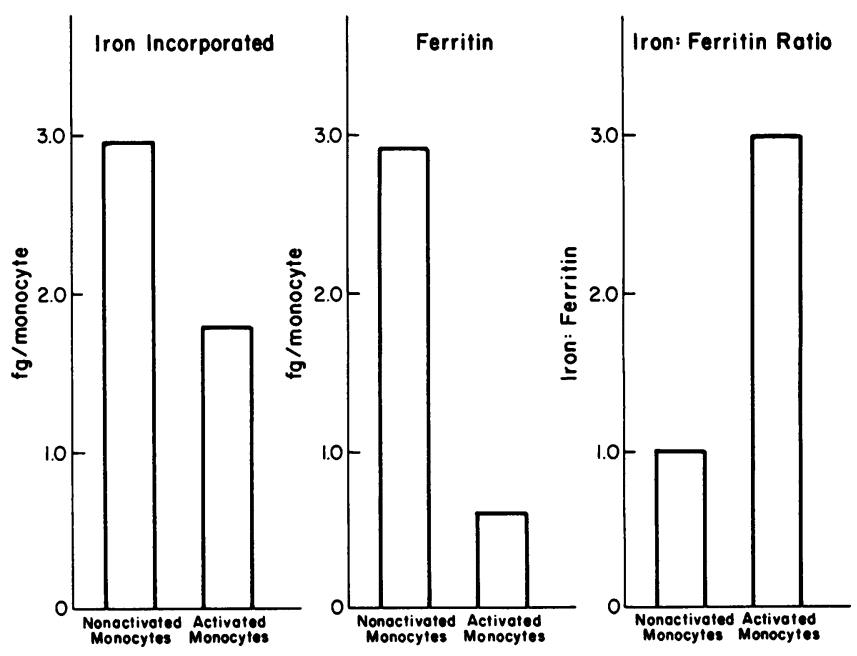

Figure 3. Ferritin in IFN $\gamma$-activated monocytes is saturated with approximately three times as much newly incorporated iron as ferritin in nonactivated monocytes. Iron incorporation (left panel) and ferritin content (middle panel) were measured in parallel in IFN $\gamma$-activated and nonactivated monocytes from each of three subjects in four independent experiments, and the ratio of iron incorporated: ferritin (right panel) was calculated. 
for $5 \mathrm{~d}$ in the presence or absence of iron transferrin. Cultures were analyzed for transferrin receptor expression by FACS ${ }^{\circledast}$ analysis, and/or intracellular ferritin content by radioimmunoassay (Fig. 4).

Transferrin receptor expression and ferritin levels were decreased in the IFN $\gamma$-activated monocytes. When nonactivated and IFN $\gamma$-activated monocytes were incubated with iron transferrin, transferrin receptor expression was increased on both nonactivated (2.3-fold) and IFN $\gamma$-activated (3.4-fold) monocytes. Paralleling these results, ferritin content was also increased in both the nonactivated (1.3-fold) and IFN $\gamma$ activated (2.9-fold) monocytes in the presence of iron transferrin.

These results show that the physiologic iron binding protein, transferrin, in its iron saturated form, increases the expression of both transferrin receptors and intracellular ferritin in cultured human monocytes. These results also indicate that iron transferrin is able to upregulate transferrin receptor expression on IFN $\gamma$-activated monocytes to a level comparable to that seen on nonactivated monocytes incubated without iron transferrin. In contrast, while iron transferrin also upregulates intracellular ferritin content in IFN $\gamma$-activated monocytes, the increase is $>50 \%$ of that seen in nonactivated monocytes incubated without iron transferrin.

To determine if iron transferrin influences transferrin receptor expression and intracellular ferritin content in nonactivated and IFN $\gamma$-activated monocytes under serumless conditions, we assessed the influence of iron transferrin and IFN $\gamma$ on monocytes cultured in the absence of serum. In two independent experiments on monocytes from the same individual, transferrin receptor expression was upregulated by iron transferrin in both nonactivated and IFN $\gamma$-activated monocytes cultured in the absence of serum, and to a degree comparable to that in monocytes cultured in the presence of serum. Ferritin levels were also upregulated by iron transferrin in both nonactivated and IFN $\gamma$-activated monocytes cultured in the absence

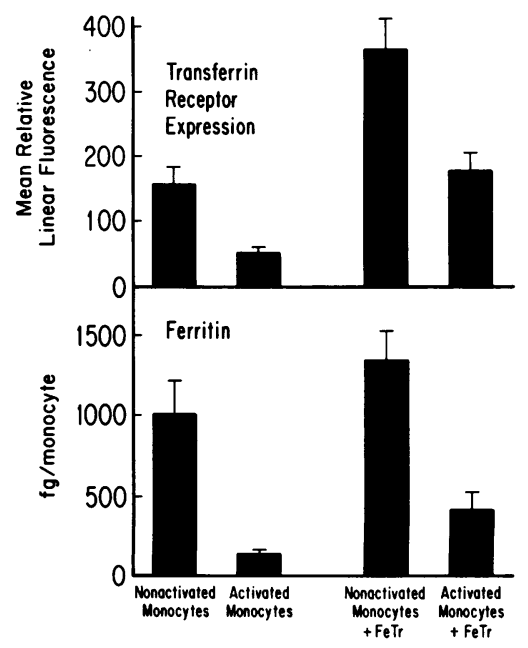

Figure 4. Iron transferrin upregulates transferrin receptors and ferritin levels in IFN $\gamma$ activated and nonactivated monocytes. Nonactivated and IFN $\gamma$-activated monocytes were incubated with iron transferrin at a concentration of $6 \mathrm{mg} / \mathrm{ml}$ for $5 \mathrm{~d}$. The monocytes were then analyzed for ferritin content $(n=5)$ by radioimmunoassay and/or transferrin receptor expression ( $n$ $=7$ ) by FACS analysis.

For transferrin receptor expression and ferritin content, comparing nonactivated to IFN $\gamma$-activated monocytes, $P<0.01$ and $P<0.02$ respectively; nonactivated to nonactivated monocytes with iron transferrin, $P<0.01$ and $P<$ 0.05 respectively; IFN $\gamma$-activated to IFN $\gamma$-activated monocytes with iron transferrin, $P<0.01$ and $P<0.05$, respectively, by paired, twotailed $t$ test. Data are the mean \pm SEM. of serum, again to a degree comparable to that of monocytes cultured in the presence of serum.

In these studies, we chose to incubate monocytes with an iron transferrin concentration of $6 \mathrm{mg} / \mathrm{ml}$, because in a previous study, this concentration was nontoxic and completely reversed the capacity of IFN $\gamma$-activated monocytes to inhibit L. pneumophila multiplication (3). While this concentration is at the high end of the physiologic range, concentrations of iron transferrin at least as low as $0.7 \mathrm{mg} / \mathrm{ml}$, well within the physiologic range, partially but significantly reversed activation in that study (3).

\section{Discussion}

Our study shows that IFN $\gamma$ unidirectionally downregulates both transferrin receptor expression and intracellular ferritin content in human mononuclear phagocytes, whereas iron transferrin unidirectionally upregulates these two key molecules in cellular iron metabolism. Iron transferrin upregulates transferrin receptor expression and intracellular ferritin content in both nonactivated and activated human monocytes. Iron transferrin thus appears to influence its own uptake in both nonactivated and activated monocytes via a positive feedback mechanism, i.e., by increasing transferrin receptor expression. This finding is consistent with our previous finding showing that iron-saturated transferrin reverses the inhibitory effect of IFN $\gamma$ against the intracellular bacterial pathogen $L$. pneumophila.

Another group of investigators also has demonstrated that the regulation of transferrin receptors and ferritin in nonactivated human monocytes is unidirectional as opposed to the bidirectional regulation observed in other cell types, and that iron salts increase transferrin receptor expression and ferritin content in nonactivated monocytes (15). However, in contrast to our findings, Taetle and Honeysett reported bidirectional regulation of transferrin receptor expression (upregulated) and ferritin content (downregulated) in IFN $\gamma$-activated human mononuclear phagocytes, as occurs in other cell types (16). Also in contrast to our study, Taetle and Honeysett reported that IFN $\gamma$ induced increased release of iron from monocytes (16). These discrepancies may be due to one or more methodological differences. First, we assayed transferrin receptor expression and intracellular ferritin content in monocytes after 5 $\mathrm{d}$ exposure to IFN $\gamma$ or iron transferrin, whereas Taetle and Honeysett assayed cells after relatively short exposures to IFN $\gamma$ $(14-16 \mathrm{~h})$ or iron transferrin $(6 \mathrm{~h}, 14-16 \mathrm{~h})$. We wonder if measurements of transferrin receptor expression and ferritin content after such short exposures might be influenced by the extensive membrane remodeling and redistribution of intracellular membrane pools induced by IFN $\gamma$, particularly in large monocyte-derived macrophages studied by Taetle and Honeysett (see below), and thus not reflect steady state conditions reached after the cell has reached a new equilibrium. This might result in a transient increase in transferrin receptor expression. At the same time, a transient redistribution of iron transferrin or iron to intravesicular compartments in IFN $\gamma$ activated cells might result in enhanced iron release. Indeed, in the Taetle and Honeysett study, newly internalized iron was never shown to be incorporated into ferritin. Second, in our study, we studied the effects of IFN $\gamma$ by freshly isolated monocytes whereas Taetle and Honeysett studied monocyte-derived 
macrophages. We suspect that study of the effects of IFN $\gamma$ on freshly isolated monocytes may be more relevant to the in vivo situation because of evidence that the most important effector cells activated by IFN $\gamma$ at sites of infection or inflammation are newly incoming blood monocytes and not resident macrophages. Third, we cultured monocytes in autologous human serum, whereas Taetle and Honeysett cultured cells in fetal calf serum, which differs substantially from human serum in endotoxin content and iron saturation.

Our findings must be viewed in the context of what has been recently learned regarding the regulation of transferrin receptors and intracellular ferritin in cellular iron metabolism at the molecular level.

The unidirectional regulation of transferrin receptors and intracellular ferritin in nonactivated human mononuclear phagocytes is in marked contrast to the bidirectional regulation of these molecules in other cell types. In various other cell types and tumor cell lines this regulation is bidirectional:excess iron entering the cell downregulates transferrin receptor expression and upregulates ferritin concentration (12). This bidirectional regulation allows these cells to limit further uptake of iron and increase intracellular iron storage, and thereby perhaps avoid toxic effects of iron. Recent work has demonstrated the molecular basis which underlies this regulation. Iron in excess of cellular requirements results in increased translation of ferritin mRNA and a decrease in the stability of transferrin receptor mRNA. This regulation is mediated by stem loop-shaped structures termed iron-responsive elements (IREs) ${ }^{1}$ that exist within the $5^{\prime}$ untranslated region of the ferritin mRNA and the 3 ' untranslated region of the transferrin receptor mRNA (17). The IREs from both types of mRNA interact with a cytoplasmic protein named the iron-responsive element binding protein (IRE-BP) (18-20). This cytosolic protein exists in two forms with differing affinity constants for the IRE. The differing affinities are based on the reversible oxidation reduction of one or more sulfhydryl groups in the protein. In cells deprived of iron with an iron chelator, the IRE-BP is predominantly in the reduced form and binds to the IRE with high affinity resulting in increased stability and translation of transferrin receptor mRNA and decreased translation of ferritin mRNA. On the other hand, in cells treated with iron virtually all the IRE-BP is in a oxidized form and has a low affinity for the IRE resulting in decreased stability and translation of transferrin receptor mRNA and increased translation of ferritin mRNA (21). Recent data suggest that the IRE-BP has a high degree of structural similarity to the iron-containing enzyme aconitase. It has been speculated that the aconitases and the IRE-BP are members of a family of proteins, the common feature being iron sulfur centers which are able to sense alterations in iron availability (22).

Ferritin is the major iron storage protein in the human body. A major protein of mononuclear phagocytes, ferritin is found predominantly within the cytosol of cells where it can be visualized by electron microscopy as small electron-dense structures. There is evidence that ferritin is regulated differently in mononuclear phagocytes than in other cells. Unlike cells with bidirectional regulation, in monocytes maturing into macrophages in the presence or absence of iron salts, ferritin

1. Abbreviations used in this paper: IRE, iron-responsive elements; IRE-BP, IRE binding protein. levels show an increase rather than a decrease (15). The mechanisms accounting for this dichotomy are at present unknown, but it has been suggested that molecular mechanisms other than IRE-BP may be involved in ferritin gene expression in mononuclear phagocytes (23). Along this line, in maturing monocytes, ferritin levels and transferrin receptor expression show different dependencies on serum in our study. When we cultured monocytes in the absence of serum, transferrin receptor expression increased to the same level as in monocytes cultured in the presence of serum. This is consistent with baseline transferrin receptor expression in monocytes being a maturational phenomenon, independent of iron. In contrast, ferritin levels were significantly reduced in monocytes cultured in the absence of serum relative to those cultured in the presence of serum, suggesting that the baseline level of ferritin expression is dependent upon some factor in serum, possibly iron.

Our data indicates that the regulation of transferrin receptor expression and ferritin content in IFN $\gamma$-activated human monocytes remains unidirectional but is downmodulated relative to nonactivated control cells. One possible mechanism for this is that there is decreased transcription and/or posttranscriptional modification of transferrin receptor and ferritin genes in the IFN $\gamma$-activated monocyte. IFN $\gamma$ has been found to downregulate gene transcription and post-transcriptionally modify certain genes in macrophages and other cell types (24, 25 ). Thus, even if iron salts increase reduced IRE-BP (with increased stability and translation of transferrin receptor mRNA) in IFN $\gamma$-activated monocytes as in nonactivated monocytes, if less transferrin receptor genes are expressed in the IFN $\gamma$-activated monocyte, transferrin receptor expression would be less than that in nonactivated monocytes incubated with iron.

Alternatively, and along this line, the level of IRE-BP might be decreased in the IFN $\gamma$-activated monocyte with the result that less would be available to bind to transferrin receptor mRNA.

Our study suggests that a qualitative change in intracellular ferritin occurs in the IFN $\gamma$-activated monocyte. In parallel with the downregulation in transferrin receptor expression and ferritin concentration, iron incorporation is reduced in IFN $\gamma$ activated monocytes. However, the mean reduction in iron incorporation (33\%) is quantitatively lower than the reduction in transferrin receptor expression (73\%) and ferritin content $(82 \%)$. The net result of this is that the ferritin remaining in IFN $\gamma$-activated monocytes is approximately three times more saturated with incorporated iron than the ferritin in nonactivated monocytes. This suggests that the stoichiometry of iron binding to ferritin is altered in the IFN $\gamma$-activated monocyte. Along this line, other studies have reported that ferritin exists in two different forms, one containing low amounts of iron and one high amounts of iron, and that these forms interact differently with iron. High iron ferritin takes up iron rapidly and releases it slowly relative to low iron ferritin (26). If the ferritin in IFN $\gamma$-activated monocytes is of the high iron type, as our study suggests, its interaction with iron would be such as to decrease cytosolic iron. A decrease in cytosolic iron in the IFN $\gamma$-activated monocyte would also be consistent with our previously published finding that IFN $\gamma$-activated monocytes inhibit $L$. pneumophila intracellular multiplication by limiting the availability of iron.

It has been proposed that a high degree of cross-linking of low iron ferritin subunits secondary to posttranslational modifi- 
cations underlies the difference in the interactions of high and low iron ferritin with iron (26). Possibly, IFN $\gamma$ limits posttranslational modifications of ferritin, thereby increasing the cellular content of high iron ferritin. In addition, ferritin within cells is composed of two different subunit types, $\mathrm{H}$ and $\mathrm{L}$. Freshly isolated monocytes contain a preponderance of $\mathrm{H}$ ferritin. During monocyte to macrophage differentiation, $L$ ferritin markedly increases while $\mathrm{H}$ ferritin levels remain relatively constant (15). It has been proposed, based on several experimental models, that $\mathrm{H}$ ferritin is involved in recycling iron to the intermediate labile iron pool for metabolic processes, while $\mathrm{L}$ ferritin is involved in long-term iron storage $(27,28)$. Thus, the influence of IFN $\gamma$ on the expression of these subunits may ultimately determine its effect on iron metabolism in the cell.

Our previous studies have demonstrated that IFN $\gamma$-activated monocytes inhibit L. pneumophila intracellular multiplication by limiting the availability of iron. Our previous finding that IFN $\gamma$-activated monocytes downregulate transferrin receptor expression provided one potential mechanism by which IFN $\gamma$-activated monocytes might limit iron availability, i.e., by decreasing iron uptake (3). Our finding in the present study that IFN $\gamma$-activated monocytes also downregulate intracellular ferritin content provides a second potential mechanism by which IFN $\gamma$-activated monocytes might limit iron availability. By decreasing intracellular ferritin content, fewer ferritin molecules would be available to release iron to the intermediate iron pool, either by undergoing degradation in lysosomes or another mechanism.

Our previous work and this study expand the role of cytokines into the area of mononuclear phagocyte transferrin receptor and ferritin regulation. This has important implications for both infection and the inflammatory response. Two mediators of inflammation, IL-1 and TNF alpha, have been shown to stimulate mononuclear phagocytes as well as other cell types to synthesize intracellular ferritin and store increased amounts of intracellular iron (29-34). The synthesis of these cytokines is increased in a variety of infectious and noninfectious states, and these cytokines are felt to play a role in the hypoferremia seen in sepsis and chronic disease (35-38). In the host infected with certain intracellular pathogens, this effect of IL-1 and TNF-increasing mononuclear phagocyte iron and ferritin may be detrimental (39). IFN $\gamma$, a cytokine more specific to the cell-mediated immune response against intracellular pathogens, may play an important role in counteracting the influence of IL-1 and TNF on iron metabolism in mononuclear phagocytes. On the other hand, TNF has been found in some instances to act in a cooperative, synergistic fashion with IFN $\gamma$ against infections with intracellular pathogens $(40,41)$ raising the question of whether there is a composite effect of IFN $\gamma$ and TNF on cellular iron metabolism. These interactions may be complex and may play an important role in converting the mononuclear phagocyte from a passive storage organ of intracellular iron into a cell with antimicrobial capabilities able to limit intracellular iron to pathogens and/or use iron to arm antimicrobial killing mechanisms.

\section{Acknowledgments}

We are grateful to Ms. Barbara Jane Dillon and Mr. Chai Chaloyphian for expert technical assistance with experiments, and to Ms. Ingrid Schmidt for expert technical assistance with flow cytometry.
This work was supported by grants AI-22421 and AI-28825 from the National Institutes of Health. The JCCC Flow Cytometry Core Laboratory at UCLA is supported by National Institutes of Health Grant CA-16042. Dr. Horwitz is Gordon MacDonald Scholar at University of California, Los Angeles. During part of the time this work was performed, Dr. Byrd was a recipient of a National Research Service Award from the National Institutes of Health. Dr. Horwitz was recipient of a Faculty Research Award from the American Cancer Society.

\section{References}

1. Finch, C. A., and H. Huebers. 1982. Perspectives in iron metabolism. $N$ Engl. J. Med. 306:1520-1528.

2. Britigan, B. E., J. S. Serody, M. B. Hayek, G. M. Charniga, and M. S. Cohen. 1991. Lactoferrin uptake by mononuclear phagocytes. J. Immunol. 147:4271-4279.

3. Byrd, T. F., and M. A. Horwitz. 1988. Interferon gamma-activated human monocytes downregulate transferrin receptors and inhibit the intracellular multiplication of Legionella pneumophila by limiting the availability of iron. J. Clin. Invest. 83:1457-1465.

4. Byrd, T.F., and M. A. Horwitz. 1991. Chloroquine inhibits the intracellular multiplication of Legionella pneumophila by limiting the availability of iron. A potential new mechanism for the therapeutic effect of chloroquine against intracellular pathogens. J. Clin. Invest. 88:351-357.

5. Byrd, T. F., and M. A. Horwitz. 1991. Lactoferrin inhibits or promotes Legionella pneumophila intracellular multiplication in nonactivated and interferon gamma-activated human monocytes depending upon its degree of iron saturation. Iron-lactoferrin and nonphysiologic iron chelates reverse monocyte activation against Legionella pneumophila. J. Clin. Invest. 88:1103-1112.

6. Horwitz, M. A., and S. C. Silverstein. 1980. The Legionnaires' disease bacterium (Legionella pneumophila) multiplies intracellularly in human monocytes. J. Clin. Invest. 74:771-782.

7. Methods in Enzymology: Peptide Growth Factors. Part B. 1987. Edited by D. Barnes, D., and D. A. Sirbasku, editors. Academic Press Inc. Harcourt Brace Jovanovich, New York. p. 274.

8. Musson, R. A. 1983. Human serum induces maturation of human monocytes in vitro. Changes in cytolytic activity, intracellular lysosomal enzymes, and nonspecific esterase activity. Am. J. Pathol. 111:331-340.

9. Maoz, H., A. Polliack, V. Barak, S. Yatziv, S. Biran, H. Biloh, and A. J. Treves. 1986. Parameters affecting the in vitro maturation of human monocytes to macrophages. Int. J. Cell Cloning. 4:167-185.

10. Summers, M., M. Worwood, and A. Jacobs. 1974. Ferritin in normal erythrocytes, lymphocytes, polymorphs, and monocytes. Br. J. Haematol. 28:1926.

11. Andreesen, R., H. Osterholz, K. J. Bodemann, K. J. Bross, U. Costabel, and G. W. Lohr. 1984. Expression of transferrin receptors and intracellular ferritin during terminal differentiation of human monocytes. Blut. 49:195-202.

12. Mattia, E., and J. van Renswoude. 1988. The pivotal role of ferritin in cellular iron homeostasis. Bioessays. 8:107-111.

13. Jacobs, A. 1977. Low molecular weight intracellular iron transport compounds. Blood. 50:433-439.

14. Pollack, S., P. Aisen, F. D. Lasky, and G. Vanderhoff. 1976. Chelate mediated transfer of iron from transferrin to desferrioxamine. $\mathrm{Br}$. J. Haematol. 34:231-235.

15. Testa, U., M. Petrini, M. T. Quaranta, E. Pelosi-Testa, G. Mastroberardino, A. Camagna, G. Boccoli, M. Sargiacomo, G. Isacchi, A. Cozzi, et al. 1989. Iron up-modulates the expression of transferrin receptors during monocytemacrophage maturation. J. Biol. Chem. 264:13181-13187.

16. Taetle, R., and J. M. Honeysett. 1988. Gamma-interferon modulates human monocyte/macrophage transferrin receptor expression. Blood. 71:15901595.

17. Casey, J. L., M. W. Hentze, D. M. Koeller, S. W. Caughman, T. A. Rouauttt, R. D. Klausner, and J. B. Harford. 1988. Iron-responsive elements: regulatory RNA sequences that control mRNA levels and translation. Science (Wash. DC). 240:924-928.

18. Leibold, E. A., and H. N. Munro. 1988. Cytoplasmic protein birds in vitro to a highly conserved sequence in the 5 ' untranslated region of ferritin heavy and light subunit mRNAs. Proc. Natl. Acad. Sci. USA. 85:2171-2175.

19. Rouault, T. A., M. W. Hentze, S. W. Caughman, J. B. Harford, and R. D. Klausner. 1988. Binding of a cytoplasmic protein to the iron-responsive element of human ferritin messenger RNA. Science (Wash. DC). 241:1207-1210.

20. Mullner, E. W., B. Neupert, and L. C. Kuhn. 1989. A specific mRNA binding factor regulates the iron-dependent stability of cytoplasmic transferrin receptor mRNA. Cell. 58:373-382.

21. Hentze, M. W., T. A. Rouault, J. B. Harford, and R. D. Klausner. 1989. Oxidation-reduction and the molecular mechanism of a regulatory RNA-protein interaction. Science (Wash. DC). 244:357-359. 
22. Rouault, T. A., C. D. Stout, S. Kaptain, J. B. Harford, and R. D. Klausner. 1991. Structural relationship between an iron-regulated RNA-binding protein (IRE-BP) and aconitase: functional implications. Cell. 64:881-883.

23. Testa, U., L. Kuhn, M. Petrini, M. T. Quaranta, E. Pelosiard, and C. Peschle. 1991. Differential regulation of iron regulatory element-binding protein (s) in cell extracts of activated lymphocytes versus monocytes-macrophages. J. Biol. Chem. 266:13925-13930.

24. Radzioch, D., and L. Varesio. 1991. c-fos mRNA expression in macrophages is downregulated by interferon gamma at the posttranscriptional level Mol. Cell. Biol. 11:2718-2722.

25. Kung, A. W. C., and K. S. Lau. 1990. Interferon gamma inhibits thyrotropin-induced thyroglobulin gene transcription in cultured human thyrocytes. $J$. Clin. Endocrinol. Metab. 70:1512-1517.

26. Mertz, J. R., and E. C. Theil. 1983. Subunit dimers in sheep spleen apoferritin. The effect on iron storage. J. Biol. Chem. 258:11719-11726.

27. Jacobs, A. 1985. Ferritin: an interim review. Curr. Top. Hematol. 5:2562.

28. Pattanapanyasat, K. 1989. Expression of isoferritins in peripheral blood lymphocytes: effect of phytohaemagglutinin and iron. Eur. J. Haematol. 43:143149.

29. Rogers, J. T., K. R. Bridges, G. P. Durmonwicz, J. Glass, P. E. Auron, and H. N. Munro. 1990. Translational control during the acute phase response. Ferritin synthesis in response to Interleukin-1. J. Biol. Chem. 24:14572-14578.

30. Wei, Y., S. C. Miller, Y. Tsuji, S. Torti, and F. M. Torti. 1990. Interleukin 1 induces ferritin heavy chain in human muscle cells. Biochem. Biophys. Res. Commun. 169:289-296.

31. Brock, J. H., and X. Alvarez-Hernandez. 1989. Modulation of macrophage iron metabolism by tumor necrosis factor and interleukin 1. FEMS (Fed. Eur. Microbiol. Soc.) Microbiol. Immunol. 47:309-310.
32. Alvarez-Hernandez, X., J. Liceaga, I. C. McKay, and J. H. Brock. 1989. Induction of hypoferremia and modulation of macrophage iron metabolism by tumor necrosis factor. Lab. Invest. 61:319-322.

33. Torti, S. V., E. L. Kwak, S. C. Miller, L. L. Miller, G. M. Ringold, K. B. Myambo, A. P. Young, and F. M. Torti. 1988. The molecular cloning and characterization of murine ferritin heavy chain, a tumor necrosis factor-inducible gene J. Biol. Chem. 263:12638-12644.

34. Tanaka, T., E. Araki, K. Nitta, and M. Tateo. 1987. Recombinant human tumor necrosis factor depresses serum iron in mice. J. Biol. Response Modif. 6:484-488.

35. Lahdevirta, J., C. P. J. Maury, A. Teppo, and H. Repo. 1988. Elevated levels of circulating cachectin/tumor necrosis factor in patients with acquired immunodeficiency syndrome. Am. J. Med. 85:289-291.

36. Roux-Lombard, P., C. Modoux, A. Cruchaud, and J. Dayer. 1989. Purified blood monocytes from HIV 1-infected patients produce high levels of TNF alpha and IL-1. Clin. Immunol. Immunopathol. 50:374-384.

37. Beutler, B., and A. Cerami. 1987. Cachectin: more than a tumor necrosis factor. N. Engl. J. Med. 316:379-385.

38. Dinarello, C. A. 1984. Interleukin-1. Rev. Infect. Dis. 6:51-95.

39. Lalonde, R. G., and B. E. Holbein. 1984. Role of iron in Trypanosoma cruzi infection of mice. J. Clin. Invest. 73:470-476.

40. Denis, M. 1991. Killing of Mycobacterium tuberculosis within human monocytes: activation by cytokines and calcitriol. Clin. Exp. Immunol. 84:200206.

41. Portnoy, D. A., R. D. Schreiber, P. Connelly, and L. G. Tilney. 1989. Gamma interferon limits access of Listeria monocytogenes to the macrophage cytoplasm. J. Exp. Med. 170:2141-2146. 